Norbert Froese MD, Robert Friesen MD FRCPC

\title{
Measurement Techniques
}

\section{Measurement of cardiac output - trans- tracheal Doppler versus thermodilution}

The ABCOM 1 transtracheal Doppler (TTD) has been developed as a non-invasive cardiac output monitor. With this device, cardiac output is continuously calculated from ascending aortic blood flow velocity and aortic diameter obtained via an ultrasound transducer incorporated into the tip of an endotracheal tube. We evaluated the clinical use of the ABCOM I monitor and compared cardiac outputs obtained using the TTD system with simultaneous thermodilution (TD) measurements. We found the operation of the ABCOM 1 monitor to be difficult and timeconsuming. In our operating rooms, acceptable Doppler signal quality was difficult to obtain. There was no correlation between 36 simultaneously obtained TTD and TD cardiac output measurements. The average difference between measurement techniques and the limits of agreement were unacceptably large (mean difference $=3.04 \mathrm{~L} \cdot \mathrm{min}^{-1}$, mean $\pm 2 S D=-6.04$ to $\left.12.48 \mathrm{~L} \cdot \mathrm{min}^{-1}\right)$. Separately analyzing only those measurements during which Doppler signal quality was adequate did not improve agreement between TTD and TD measurements. On the basis of these findings, TTD cannot be recommended as a clinical cardiac output measurement technique.

Le doppler transtrachéal Abcom I (TTD) se veut un moniteur de débit cardiaque non-invasif. Il calcule en continu le débit cardiaque à partir de la vélocité du sang dans l'aorte ascendan-

\section{Key words}

HEART: cardiac output;

MEASUREMENT TECHNIQUES: cardiac output, echocardiography, Doppler, thermodilution.

From the Department of Anesthesia, University of Manitoba Faculty of Medicine, Winnipeg, Manitoba.

Address correspondence to: Dr. R. Friesen, Department of Anaesthesia, St. Boniface Hospital, 409 Tache Avenue,

Winnipeg, Manitoba, R2H $2 \mathrm{~A} 6$.

Accepted for publication 17th May, 1991. te et du diamètre échographique de l'aorte mesuré grâce à un cristal incorporé au bout du tube endotrachéal. Nous avons évalué en clinique la performance de l'Abcom 1 en prenant des mesures de débit par thermodilution (TD) en tant que références simultanées. L'emploi de l'Abcom 1 prenait du temps et s'est avéré difficile. De plus, en salle d'opération, il était difficile d'obtenir un signal doppler adéquat. Enfin, nous n'avons pas trouvé de corrélation entre les débits mesurés simultanément parTTD et TD à 36 reprises. Les écarts de mesure entre les deux techniques étaient beaucoup trop grands avec une différence moyenne de 3,04 L $\cdot$ min $^{-1}$ et un intervalle de confiance à $95 \%$ s'étendant de $-6,04$ à $12,48 \mathrm{~L} \cdot \mathrm{min}^{-1}$, Même en restreignant l'analyse aux couples de mesures au signal doppler de bonne qualité, on n'améliorait en rien la corrélation TTD-TD. Bref, nous ne pouvons pas cautionner l'usage clinique du TTD à titre de moniteur de débit cardiaque.

Continuous non-invasive measurement of cardiac output in $\operatorname{dogs}^{1}$ and in humans, ${ }^{2}$ using transtracheal Doppler shift measurements, has been described previously. With this technique, ascending aortic blood flow is calculated continuously using Doppler shift measurements obtained with an ultrasound transducer incorporated in the tip of an endotracheal tube. Monitoring ascending aortic blood flow involves positioning the transducer in such a manner that the ultrasonic beam bisects the ascending aorta. Prior to monitoring aortic blood flow, ascending aortic diameter is measured by identification of the proximal and distal aortic walls. Subsequently, blood flow is continuously calculated using the aortic diameter measurement and ongoing mean Doppler aortic blood velocity measurements.

Previously published reports have shown good correlation between cardiac output values obtained using the transtracheal Doppler (TTD) technique and pulmonary artery catheter thermodilution (TD) cardiac output measurements. ${ }^{2-4}$ 
This study was designed to evaluate the clinical use of the Applied Biometrics Inc. ABCOM 1 TTD cardiac output computer and to compare cardiac output measurements obtained using the TTD technique with cardiac outputs simultaneously determined by standard TD methods.

\section{Methods}

In all cases, the ABCOM 1 cardiac output computer was operated by one investigator. Initially ten patients were monitored with the ABCOM 1 system in order to familiarize this investigator with positioning of the TTD endotracheal tube and operation of the $A B C O M 1$ computer.

An additional seven patients were enrolled in the comparative study. Approval was obtained from the University of Manitoba Faculty Committee on the use of Human Subjects in Research and informed consent was obtained from each patient.

Patients scheduled for elective surgery under general anaesthesia were included in the study if a pulmonary artery catheter was indicated and the site of the proposed surgery allowed full access to the head and neck. As positioning of the TTD endotracheal tube requires periodic deflation of the cuff, patients with active upper gastrointestinal disease were excluded from the study. Also, patients with contraindications to repeated manipulation of the head and neck were excluded as this manoeuvre is also required in the positioning process. A patient with a known ascending aortic aneurysm was not included as this may interfere with TTD ascending aorta diameter and blood velocity measurements.

After induction of general anaesthesia the TTD endotracheal tube/transducer was positioned in accordance with the manufacturer's recommendations. In this procedure the position of the transducer is manipulated by adjusting the depth of the endotracheal tube and by rotating the patient's head and thus the endotracheal tube until optimum Doppler signal quality is obtained. Doppler signal quality is assessed by viewing a visual display indicating forward and reverse blood flow and by listening to an audio representation of the Doppler shift.

Measurement of the ascending aortic diameter was performed immediately following optimal positioning of the TTD endotracheal tube.

For each case, six separate TD cardiac output measurements were obtained, at least ten minutes apart. All TD measurements were performed in triplicate using $10 \mathrm{ml}$ of room temperature indicator. Injection of indicator solution was not timed with respect to the ventilatory cycle. Cardiac output calculations were performed by a Baxter COM-2 TD cardiac output computer in all cases except case 2, for which a Hewlett Packard HP 8552A computer was used.

Prior to each cardiac output measurement, the TTD endotracheal tube/transducer was re-positioned if necessary to optimize the Doppler signal. The continuously measured TTD cardiac output was averaged by the TTD computer over the time required for each TD cardiac output measurement and these results were recorded on a printer. The electrosurgical cautery unit was not used during the time of the cardiac output measurements to avoid electrical interference (other sources could still have interfered).

As TTD cardiac output measurements can be influenced by transducer positioning, the investigators were blinded to the TTD determinations of cardiac output until completion of the study. Routine clinical management of anaesthesia was dictated by data provided by the TD cardiac output determinations.

Subjective assessment of Doppler sounds (poor, fair, good, excellent) and the status of the TTD Doppler signal display (forward flow on a scale from 1-20, reverse flow 1-20) were recorded during aortic diameter measurement and during each cardiac output measurement.

Thermodilution and transtracheal Doppler cardiac output measurements were compared using regression analysis. Bias and limits of agreement with $95 \%$ confidence limits ${ }^{5}$ were also calculated.

\section{Results}

Of the seven patients studied, four had coronary artery bypass grafting, two had major abdominal vascular procedures and one had a cholecystectomy. Ages ranged from 51 to $69 \mathrm{yr}$ with a mean of $60 \mathrm{yr}$. Size eight or nine internal diameter endotracheal tubes were used in all cases.

Unexpected difficulties were encountered in obtaining good Doppler signals. This resulted in repeated and prolonged manipulations of the endotracheal tube.

Of the 42 potential simultaneous cardiac output measurements, three were lost because no TTD measurements were obtained due to poor signal quality. Also, one measurement was lost because the thermodilution result was not recorded and two measurements were not obtained due to lack of time prior to initiation of cardiopulmonary bypass.

The ABCOM 1 transtracheal cardiac output computer used in this study automatically discontinued cardiac output monitoring if the Doppler signal quality was poor. As this occurred frequently, TTD cardiac output monitoring was discontinuous during a further 17 cardiac output measurements. These measurements were included in our analysis.

The 36 simultaneous measurements are illustrated in Figures 1 and 2. Regression analysis of the data showed no correlation between TD and TTD thermodilution measurements $\left(r^{2}=0.02\right)$.

The mean difference between cardiac output measure- 


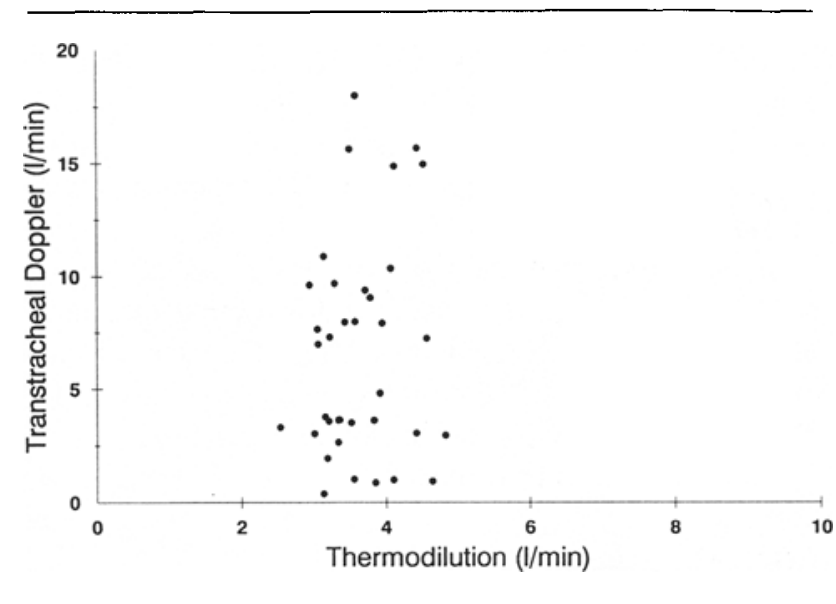

FIGURE 1 Transtracheal Doppler vs thermodilution cardiac output for simultaneously obtained measurements.

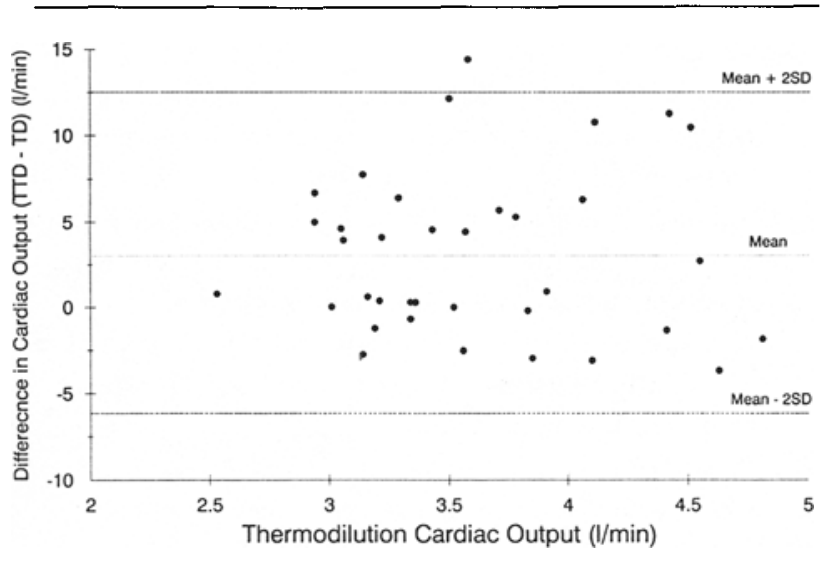

FIGURE 2 Difference between measurement techniques vs thermodilution cardiac output.

ments (TTD-TD) was $3.04 \mathrm{~L} \cdot \mathrm{min}^{-1}$ and had a $95 \%$ confidence interval of 1.44 to $4.64 \mathrm{~L} \cdot \mathrm{min}^{-1}$. The standard deviation of the differences was $4.72 \mathrm{~L} \cdot \mathrm{min}^{-1}$ and the limits of agreement were from -6.40 to 12.48 $\mathrm{L} \cdot \mathrm{min}^{-1}$. The $95 \%$ confidence interval for the lower limits was -3.24 to $-8.81 \mathrm{~L} \cdot \mathrm{min}^{-1}$ and for the upper limits was 9.71 to $15.2 \mathrm{~L} \cdot \mathrm{min}^{-1}$.

\section{Discussion}

Regression analysis of the data demonstrated that there was correlation between TTD and TD measurements of cardiac output. This statistical approach, however, can be misleading when it is used to compare two methods of clinical measurement. ${ }^{5}$ Measurement techniques which agree closely can show poor correlation if the range of the measured variable is narrow. Limits of agreement, which are calculated from the bias or mean difference between measurements and the standard deviation of the bias (d \pm
$2 \mathrm{SD}$ ), are a more appropriate method of comparing measurement techniques. ${ }^{5}$ Two methods of measurement can generally be considered interchangeable if the limits of agreement fall within a clinically acceptable range. This was not the case in this study.

The large variability between TTD and TD could be due to variability within either of both techniques. Our TD cardiac output measurements were obtained with standard techniques and equipment. The within-technique variability for TD cardiac output measurements has been reviewed by Stetz et al. ${ }^{6}$ The reported standard error of the mean of repeated TD cardiac output measurements when performed in triplicate ranges from 2.0 to $5.0 \%$. Also in this study, TD cardiac output measurements were consistent with the patients' clinical status. We therefore believe that the TTD measurements of cardiac output accounted for most of the between-technique variability that was observed.

Our TD indicator injections were not timed with respect to the ventilatory cycle and this may have increased their variability. However, TD measurements consisting of the average of randomly timed single determinations are more representative of true average cardiac output and therefore more appropriate for comparison with TTD, which also measures average cardiac output throughout all phases of respiration. ${ }^{\text {? }}$

There are many possible causes of error and variability in cardiac output measurement with the TTD. Errors can occur in the initial measurement of aortic diameter, the measurement of blood flow velocity, the manipulation of the ultrasound signals and the calculations. Proper positioning of the transducer, which can never be assured, is critical to the measurement of both aortic diameter and blood flow velocity. The angle of the ultrasound beam with respect to blood flow, which also affects both diameter and velocity measurements, cannot be measured, so an empirically derived angle is used and this may cause an error of $14 \%$ in the measurement of cardiac output. $^{4}$

In our hands, attempts at obtaining and maintaining good Doppler signals with the TTD cardiac output monitor proved to be difficult and time-consuming. Often these attempts were futile resulting in no signal or obviously inadequate signal quality. The cause of this difficulty is unknown. Possible causes include electromagnetic interference in our operating rooms or limitations of the software. This difficulty may also be inherent in the technique of endotracheal placement of the ultrasound transducer.

Because of the large variability poor signal quality may have introduced to the TTD cardiac output measurements, the 16 measurements during which signal quality was acceptable (sound quality good or excellent and reverse flow $\leq 6$ ) were analyzed separately. Signal quality was 


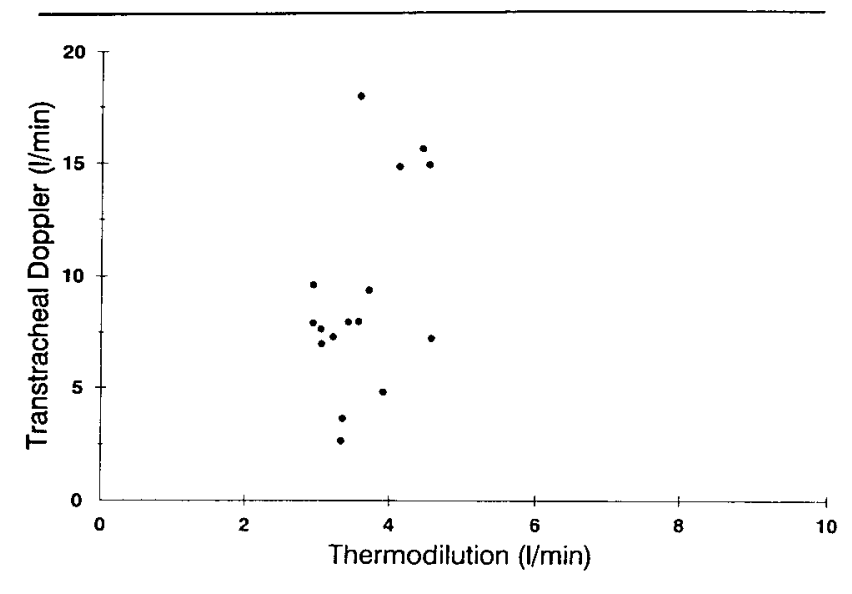

FIGURE 3 Transtracheal Doppler vs thermodilution cardiac output for measurements with acceptable signal quality.

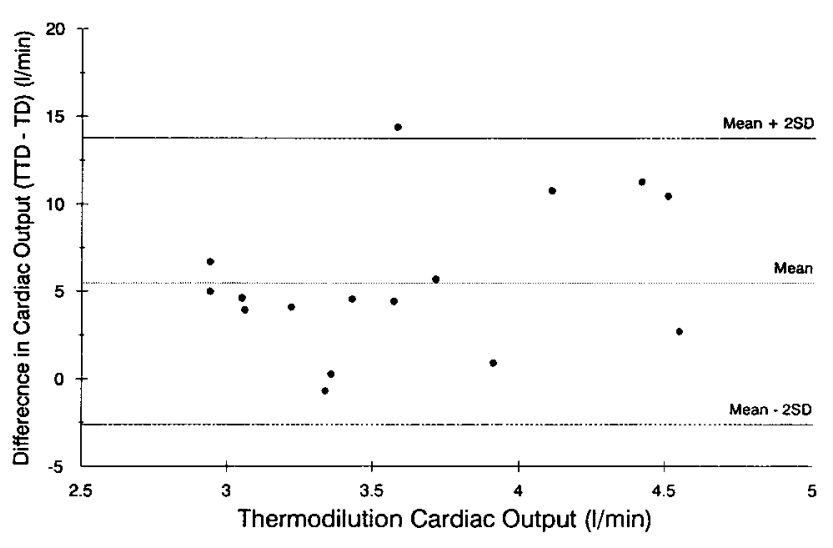

FIGURE 4 Difference between techniques vs thermodilution cardiac output for measurements with acceptable signal quality.

also acceptable during the aortic diameter determination for all these measurements. These measurements are shown in Figures 3 and 4 . Again the correlation was poor $\left(r^{2}=0.21\right)$. The calculated bias (TTD-TD) was 5.57 $\mathrm{L} \cdot \mathrm{min}^{-1}$, with a $95 \%$ confidence interval of 3.40 to 7.74 $\mathrm{L} \cdot \mathrm{min}^{-1}$. The limits of agreements were from -2.63 to $13.77 \mathrm{~L} \cdot \mathrm{min}^{-1}$. The $95 \%$ confidence interval for the lower limit was -6.39 to $1.13 \mathrm{~L} \cdot \mathrm{min}^{-1}$ and for the upper limit was 10.0 to $17.5 \mathrm{~L} \cdot \mathrm{min}^{-1}$. The poor agreement of these measurements is of particular concern because during these measurements there were no indications of unreliable TTD cardiac output measurement.

All persons were blinded to the transtracheal Doppler cardiac output measurements during the conduct of this study. In previous studies showing good correlation between TTD and TD cardiac output computers the investigators were not similarly blinded. We believe blinding is important as transtracheal Doppler measured cardiac output may be altered by relatively small changes in endotracheal tube position. A blinded study more closely reflects the clinical use of the monitor where signal quality is the only indicator of the reliability of the cardiac output measurements.

In summary, we found the ABCOM 1 cardiac output computer was difficult to use. Cardiac output measurements obtained with the transtracheal Doppler cardiac output computer did not agree with simultaneously obtained thermodilution cardiac output measurements in our operating room environment.

\section{Acknowledgements}

The authors wish to thank Mrs. Anne Cameron for secretarial assistance and Dr. R. Hudson for helpful suggestions. This research was funded in part by Medigas Incorporated.

\section{References}

1 Abrams JH, Weber RE, Holmen KD. Transtracheal Doppler: a new method of continuous cardiac output measurement. Anesthesiology 1989; 70: 134-8.

2 Abrams JH, Roland EW, Kenneth DH. Continuous cardiac output determination using transtracheal Doppler: initial results in humans. Anesthesiology 1989; 71: 11-5.

3 Yoshitake S, Matsumoto S, Miyakawa H et al. Intraoperative cardiac output monitoring by transtracheal Doppler tube. Can J Anaesth 1990; 37: S1 10.

4 Peper J, Biervliet JD, de Jong AP, Kloek JJ, van Hardevelt $F W$. Comparison of cardiac output from continuous transtracheal Doppler with standardized thermodilution. Anesthesiology 1990; 73: A530.

5 Bland JM, Altman DG. Statistical methods for assessing agreement between two methods of clinical measurement. Lancet 1986; 1: 307-10.

6 Stetz CW, Miller RG, Kelly GE et al. Reliability of the thermodilution method in the determination of cardiac output in clinical practice. Am Rev Respir Dis 1982; 126: 1001-4.

7 Snyde JV, Powner DU. Effects of mechanical ventilation on the measurement of cardiac output by thermodilution. Crit Care Med 1982; 10: 677-82. 